\title{
Press and Dryer Roll Surfaces and Web Transfer Systems for Ultra High Paper Machine Speeds
}

Quarterly Status Report for the period July 1999 through September 1999

Project DE-FC36-99GO10384

D. I. Orloff

November 15, 1999

The purpose of this quarterly report is to provide an overview of the project including key tasks, schedules for completion of tasks and to document accomplishments.

Project Staff : David Orloff is principle investigator of the project, while Jere Crouse, recently retired from Beloit Corp, and Fred Bloom, Northern Illinois University, are consultants. The IPST faculty and staff working on key aspects of the project are; Fred Ahrens, Tim Patterson, Hiroki Nanko, and Yulin Deng

Project Objective: The objective of the project is to provide fundamental knowledge and diagnostic tools needed to design new technologies that will allow ultra high speed web transfer from press rolls and dryer cylinders.

Deliverables: The deliverable include; 1.) A database and understanding of the mechanisms of deposition of contaminants on roll surfaces, 2.) Experimental results that demonstrate how surface chemistry, surface topology and operating conditions influence the work of adhesion in transferring webs from roll surfaces, 3.) Verification of improved web transfer models at ultra high speeds, and 4.) Development of an improved roll surface conditioning technology.

Benefits to Industry: Benefits include; 1.) Improved paper machine runnability, resulting in less breaks per day, and increased uptime, 2.) Improved utilization of first dryer section that will improve machine efficiency, energy usage, and machine speed, and 3.) Improved paper sheet surface properties as a result of reduced sheet picking.

Fundamental Questions: From a fundamental standpoint, we expect that roll surface performance depends on the composition of contaminants that deposit on these surfaces during use, as well as the materials and finishing techniques used in manufacturing these surfaces. We need to understand; the contamination process, the influence of contamination on work of adhesion, the roles of surface topology, film splitting, and process conditions on web transfer.

Key Research Tasks: Our research program may be separated into the accomplishment of six major tasks. These include;

\section{Task \#1.}

Identify composition of contaminants and topology of press and dryer roll surfaces at commercial mills. Development of techniques for measuring and quantifying surface topology of press and dryer roll 


\section{DISCLAIMER}

This report was prepared as an account of work sponsored by an agency of the United States Government. Neither the United States Government nor any agency thereof, nor any of their employees, make any warranty, express or implied, or assumes any legal liability or responsibility for the accuracy, completeness, or usefuiness of any information, apparatus, product, or process disclosed, or represents that its use would not infringe privately owned rights. Reference herein to any specific commercial product, process, or service by trade name, trademark, manufacturer, or otherwise does not necessarily constitute or imply its endorsement, recommendation, or favoring by the United States Government or any agency thereof. The views and opinions of authors expressed herein do not necessarily state or reflect those of the United States Government or any agency thereof. 


\section{DISCLAIMER}

Portions of this document may be illegible in electronic image products. Images are produced from the best available original document. 
surfaces,

Development of procedures for measuring contaminants from press roll and dryer surfaces,

Collect contaminants and surface replicas from mill surfaces. These will include fine paper, recycled liner and medium mills.

\section{Task\#2.}

Develop facilities to simulate contaminant deposition process under controlled experimental conditions.

\section{Task \#3.}

Develop facilities to simulate web transfer from contaminant surfaces and measure work of adhesion.

Defining the design targets of the apparatus,

Design of the web adhesion simulator apparatus,

Construction of the apparatus,

Testing and debug.

\section{Task \#4.}

Develop empirical models of contamination, adhesion, and picking.

Define model contamination systems,

Simulate contamination process in the lab and compare to mill data,

Simulate pressing, drying and web transfer and measure work of adhesion and picking,

Explore variables and develop correlations.

\section{Task \#5.}

Develop and verify models to predict various aspects of web transfer at ultra-high paper machine speeds. These aspects will include; peel angle, tension, and picking.

Incorporate correlations into a web transfer model,

Evaluate the web transfer model on a pilot paper machine.

Verify at Mills.

\section{Task \#6.}

Develop and demonstrate new roll surface conditioning technologies, including the PTFE roll wiping technology for use on dryer cylinder rolls.

Develop contamination control options on the roll test stand,

Develop options for controlling roll surface topology on the roll test stand,

Evaluate desirable options on the pilot paper machine.

Progress: In this section we briefly summarize the progress that we have made on each of the key research tasks.

Progress on Task \#1. As of this date we have collected contaminant samples and surface replicas from four paper machines. These include two coated free sheet machines, a linerboard machine and a medium machine. Contaminant chemical analysis, contact angle and underlying roll surface topology has been completed for the coated free sheet machines. Testing has just begun on the samples taken from the linerboard and medium machines. Results are expected by January 2000 . In the later two cases we were able to take replicas of the contaminated surfaces and should be able to not only measure the topology of the underlying cast iron roll but also that of the contaminated surface. Also for the later two cases we 
evaluated a procedure that should allow us to determine the density and thickness of the contaminant.

Progress on Task \#2: The roll surface coupons and ring system has been fabricated and installed on the refurbished roll test stand. We have developed a system for controlling the contaminant environment that the coupons are exposed to. This includes the metering of a model contaminant mixture onto a specially designed cellulose dryer felt. The felt can then be mechanically loaded against the heated coupons at commercial dryer speeds. We are currently in the process of going through system tests and shakedown experiments. These are expected to be completed within the next few weeks. In the mean time, we are measuring the topology of cast iron and chrome plated steel coupons that will be used in early contamination experiments.

Progress on Task \#3: The design and construction of the web adhesion and drying simulator (WADS) is nearing completion. We are currently designing three paper feed and loading systems. Two systems (short dwell time and long dwell time) will simulate the felt loading that occurs during cylinder drying while the third system will simulate roll pressing. We anticipate starting the debug of the short dwell time dryer feed and loading system this week.

Progress on Task \#4: We have had discussions a paper chemical vendor member company and felt supplier member company to help define a model contaminant for coated free sheet experiments. Once we have analyzed our data from the linerboard and medium mills we will be able to define model contaminant systems for these grades. We are also in the process of completing a literature survey on the paper physics involved in picking and are preparing hand sheets for adhesion and picking experiments to be conducted on WADS. We anticipate starting contamination and web adhesion experiments in December and will be prepared to report preliminary results in the spring of 2000 .

Beloit Corporation is currently preparing cast iron coupons at various commercially practical levels of roughness for our evaluation. They are also preparing proprietary coatings for evaluation as advanced press and dryer roll surfaces.

Progress on Task \#5: No progress to date.

Progress on Task \#6: No progress to date. 